\title{
Outcome of pregnancies in pregnant women with pulmonary hypertension: a single-center experience from East China
}

\author{
Huixian Miao ${ }^{1}$, Jianhua Lin $^{1}$, Yunyan $\mathrm{Chen}^{1}$, Chuan $\mathrm{Wang}^{2}$, and Taotao Huang ${ }^{2}$ \\ ${ }^{1}$ Shanghai Jiao Tong University School of Medicine Affiliated Renji Hospital \\ ${ }^{2}$ Affiliation not available
}

November 4, 2020

\begin{abstract}
In this study, we aim to find out maternal and fetal outcomes in women with PH resulting from different causes and try to determine the risk factors related to adverse maternal and fetal outcomes. We extracted the data from the records: the demographic information, onset, course, clinical and echocardiographic details, maternal and fetal complications, management as well as obstetric data, which included complications, infant of low-birth weight. We compared the outcome based on the cause of disease and pulmonary hypertension pressure levels. 603 women were included in the final analysis, who were mainly had pulmonary hypertension secondary to congenital heart disease $(66.0 \%)$ and 46 of whom had Eisenmenger syndrome (7.6\%). The mortality was $3.0 \%, 56 \%$ of which was caused by Eisenmenger syndrome. The abortion rate was $8.3 \%$ and $32 \%$ of live newborns were born before term. Heart failure complicated $17.1 \%$ and fetal growth restriction $3.5 \%$ of pregnancies. Advanced medication was administered in an increasing number of patients. Morbidity was significantly increased in women with pulmonary hypertension associated with a pulmonary hypertension pressure [?]80 $\mathrm{mmHg}$. The mortality rate was lower than previously reported. Nevertheless, in Eisenmenger syndrome, PH secondary to connective tissue disease and idiopathic $\mathrm{PH}$, the maternal mortality is still very high. In addition to the use of PAH-targeted drugs, we believe that standardized maternal management strategies can also help reduce mortality, including screening for heart disease and effective transport of critically ill patients. The maternal and infant outcome is related to etiology and the severity of PASP.
\end{abstract}

\section{Introduction}

Pulmonary hypertension $(\mathrm{PH})$ is a pathophysiological disorder which is characterized by increasing pulmonary artery pressure and pulmonary vascular resistance, and can progresses into right heart failure and death. PH has many causes and can be classified into five groups: pulmonary arterial hypertension (congenital heart disease, connective tissue disease), left heart disease (valvular disease, pulmonary stenosis, left heart inflow/outflow tract obstruction), lung disease and/or hypoxia, chronic thromboembolic pulmonary hypertension and other pulmonary artery obstructions, unclear and/or multifactorial mechanisms ${ }^{[1]}$. With advances in cardiovascular medical and surgical care, more women with PH can live up to a child-bearing age.

Cardiovascular disorder complicates $1 \%^{\sim} 3 \%$ of all pregnancies and has become a leading non-obstetric cause of global maternal death during pregnancy. Mortality remains high in pregnant women with $\mathrm{PH}$ even if pregnancy appears safe today, and it can reach as high as $50 \%$ in women with Eisenmenger's syndrome ${ }^{[2][3]}$. The hemodynamic changes and blood volume shifts related to pregnancy, labor and delivery can deliberate the right ventricle function and further heart failure. Pulmonary hypertension crisis, pulmonary thrombosis and right heart failure are the most common causes of death. The WHO recommends women with $\mathrm{PH}$ should avoid pregnancy, and if pregnancy occurs, termination should be considered as soon as possible ${ }^{[4]}$. Even if PH is considered as a contradiction for pregnancy, the incidence of pregnancy is increasing, whether planned or unplanned, and most of them choose to continue pregnancy. 
In this study, we aim to find out maternal and fetal outcomes in women with $\mathrm{PH}$ resulting from different causes and try to determine the risk factors related to adverse maternal and fetal outcomes.

\section{Methods}

We reviewed the front pages of medical records between January 1993 and December 2019 to identify pregnant women with pulmonary hypertension in Renji Hospital affiliated to Shanghai Jiao Tong University School of Medicine, which is an expert center for pregnancy complicated cardiac disease and has about 3000 deliveries per year. The diagnosis was based on the International Statistical Classification of Diseases and Related Health Problems (Ninth Version before Jan 2011, Tenth Version after Jan 2011).

Pulmonary hypertension $(\mathrm{PH})$ is defined as an increase in mean pulmonary arterial pressure (PAPm) greater than $25 \mathrm{~mm} \mathrm{Hg}$ by right heart catheterization or a pulmonary artery systolic pressure (PASP) greater than $35 \mathrm{~mm} \mathrm{Hg}$ by echocardiography if right heart catheterization is not available. A PAPm value of 25 to 35 $\mathrm{mm} \mathrm{Hg}, 36$ to $45 \mathrm{~mm} \mathrm{Hg}$, or greater than $45 \mathrm{~mm} \mathrm{Hg}$ measured by right heart catheterization correspond to the mild, moderate, or severe $\mathrm{PH}$, respectively. When it comes to diagnosis by echocardiography, a PASP value of 30 to $49 \mathrm{~mm} \mathrm{Hg}, 50$ to $79 \mathrm{~mm} \mathrm{Hg}$, not less than $80 \mathrm{~mm} \mathrm{Hg}$ correspond to the mild, moderate, or severe $\mathrm{PH}$, respectively.

Eisenmenger's syndrome is a secondary PH that develops from any left-to-right shunting cardiac lesions. The syndrome develops when pulmonary vascular resistance exceeds systemic resistance, with concomitant right-to- left shunting.

We extracted the following data from the medical records: the demographic information, onset, course, clinical and echocardiographic details, maternal and fetal complications, management as well as obstetric data, which included parity, complications regarding pregnancy such as abruption, pre-eclampsia, fetal growth restriction(FGR), the timing and mode of delivery, postpartum hemorrhage, infant of low-birth weight. Patients were classified into four groups: $\mathrm{PH}$ due to congenital heart diseases (CHD PH), PH secondary to connective tissue diseases (CNT PH), PH secondary to left heart diseases mitral/aortic valve diseases (LHD $\mathrm{PH}$ ), idiopathic $\mathrm{PH}$ (I-PH). Women with right ventricular outflow tract obstruction (pulmonary valve or supra valve stenosis) were excluded. PH secondary to left ventricular dysfunction secondary to myocardial or coronary disease were also excluded.

\section{Statistical analysis}

All analysis was performed using SPSS (22 $2^{\text {th }}$ version). We compared baseline characteristics and outcomes based on the etiology. The Fisher's exact test or Chi-square test was applied for dichotomous secondary outcome measures, while one-way ANOVA test or Kruskal-Wallis $\mathrm{H}$ test were applied for the continuous secondary outcomes. P-values of $<0.05$ were considered to indicate statistical significance (two-sided test).

\section{Results}

Data on 698 pregnant women with $\mathrm{PH}$ was available for study. After excluding 20 women with right ventricular outflow tract obstruction and 75 women with incomplete records, 603 women were included in the final analysis. Detailed information for these patients, including demographic and obstetric characteristics, etiology, advanced medication for $\mathrm{PH}$, is listed in Table 1. More baseline characteristics of women with congenital heart diseases were listed in Table 2 .

\section{Demographic and obstetric characteristics, and etiology}

The mean age was $28.49 \pm 4.89$ years. Trans-thoracic echocardiogram was used to diagnose PH in all women, and right heart catheterization was used for both diagnosis and treatment in 5(0.8\%) cases during pregnancy. Among these 603 patients, $\mathrm{PH}$ was secondary to congenital heart diseases(CHD-PH) in 398(66.0\%) women, due to left heart disease mitral/aortic valve diseases(LHD-PH) in 175(29\%) women, secondary to connective tissue diseases(CNT-PH) in 10(1.7\%) and idiopathic(I-PH) in 20(3.3\%). 398 women with CHD-PH were classified into three groups: 46(11.6\%) were Eisenmenger's syndrome(E-CHD), 142(35.7\%) were PH after 
cardiac surgery(A-CHD) and 210(52.8\%) were other PH with left-to-right shunting congenital heart diseases without cardiac surgery(O-CHD).

$449(74.5 \%)$ women were nulliparous. $352(58.4 \%)$ cases were known of the presence of heart diseases before pregnancy and $192(31.8 \%)$ cases had received cardiac surgeries before getting pregnant. The mean pulmonary arterial systolic pressure(PASP) was $54.39 \pm 24.24 \mathrm{~mm} \mathrm{Hg}$. $155(25.7 \%)$ cases were diagnosed as moderate PH and $91(15.7 \%)$ cases as severe PH respectively. The number of women with NYHA class III/IV (103, 17.1\%) were increased after getting pregnant.

\section{Management of $\mathrm{PH}$}

$490(81.3 \%)$ women counselled and visited experts regularly during pregnancy. Oral or intra-venous diuretics were used in 192(31.8\%) women, oral digoxin was used in 69(11.4\%) women, and antithrombotic prophylaxis, including oral aspirin, low-molecular-weight heparin (LMWH) or warfarin, was used in 102(16.9\%) cases. Among 43 women taking phosphodiesterase type 5 inhibitor (PDE5I), 13 still took another one or two PEtargeted medications (a prostaglandin I2 or an endothelin-receptor antagonist). Comparing the medication use between 2000 to 2009 and 2010 to 2019, there was no difference in the group of diuretics (30.30\% vs $33.20 \%$ ) and digoxin (12.70\% vs $9.60 \%$ ), with an increasing rate in the group of PAH medications $(0.60 \%$ vs $9.90 \%, \mathrm{P}=0.296)$ and antithrombotic agents $(6.10 \%$ vs $21.40 \%, \mathrm{P} ¡ 0.001)$. The details of medication use are shown in Figure 1.

\section{Maternal outcomes}

Maternal and fetal outcomes in 603 women with $\mathrm{PH}$ and in 398 women with $\mathrm{PH}$ caused by

CHD are shown in Table 3 and Table 4. 50 (8.3\%, 95CI $6.1 \%$ to $10.5 \%)$ women had abortions (i28 weeks) including two cases died before delivery, of which only $8(1.3 \%, 95 \mathrm{CI} 0.4 \%$ to $2.2 \%)$ cases were terminated pregnancy because of fetal abnormality (intrauterine fetal death or intrauterine embryo damage) and the rest of which were performed due to the disease. $551(91.4 \%, 95 \%$ CI $89.1 \%$ to $93.6 \%)$ women underwent cesarean, including 21 were performed before 28 weeks, $78(14.2 \%, 95 \mathrm{CI} 11.2 \%$ to $17.1 \%)$ of which were performed in general anesthesia. The indications were showed in Figure 2 . 243(40.3\%) were underwent emergency cesarean: $122(22 \%)$ were due to deterioration of cardiac function, $35(7 \%)$ due to onset of labor and $34(6 \%)$ due to suspected fetal distress.

Pre-eclampsia complicated $43(7.1 \%, 95 \mathrm{CI} 5.1 \%$ to $9.2 \%)$ pregnancies and intrauterine fetal growth restriction $21(3.5 \%, 95 \mathrm{CI} 2.0 \%$ to $5.0 \%)$ pregnancies. $51(8.5 \%$, 95CI $6.2 \%$ to $10.7 \%)$ women had heart failure during pregnancy. A total number of $251(35.7 \%, 95 \mathrm{CI} 32.2 \%$ to $39.3 \%)$ women were admitted to the Intensive Care Unit (ICU). 18 deaths were reported (Table S1), resulting in a maternal mortality rate of $3.0 \%$ (95CI $1.6 \%$ to $4.3 \%$ ). As the etiology of death was shown inFigure 3 , congenital heart diseases were the leading cause of maternal death. The mortality in different groups varied, which was higher in the group of E-CHD (15.2\%, 95CI $4.4 \%$ to $26.0 \%)$, CNT-PH $(10 \%, 95 \mathrm{CI}-12.6 \%$ to $32.6 \%)$, I-PH $(10.0 \%, 95 \%$ CI $-4.4 \%$ to $24.4 \%)$. 2 women died of cardiac arrest before cesarean while 16 died from uncontrolled cardiorespiratory failure after surgery. The change of the number of deaths and mortality was shown in Figure 4 .

4. Fetal outcomes

After excluding the abortion cases, the mean gestational age at delivery was $36.87+-2.71$ weeks.

The mean birthweight of 553 live-born infants was $2715+-675.00$ grams, $156(28.2 \%$, 95CI $24.4 \%$ to $32.0 \%)$ of whom were less than 2500 grams. The incidence of pre-term deliveries ( 337 weeks' gestation) was 32.0\%(95CI $28.3 \%$ to $35.7 \%$ ) in overall population.

Figure 5 showed maternal and fetal outcomes in the study population based on the PASP. In the group of PASP [?] $80 \mathrm{~mm} \mathrm{Hg}$, patients suffered from a higher rate of heart failure $\left(24.2 \%\right.$ versus $\left.5.7 \%, \mathrm{P}_{j} 0.001\right)$, to some extent, resulting in a higher admission rate to $\mathrm{ICU}(89.0 \%$ versus $33.2 \%$, $\mathrm{P} \nmid 0.001)$. Not surprisingly, maternal mortality in the population with PASP [?] $80 \mathrm{~mm} \mathrm{Hg}$ was higher than that in the patients with PASP $¡ 80 \mathrm{~mm} \mathrm{Hg}(12.1 \%$ versus $1.4 \%, \mathrm{P}\lceil 0.001)$. As a result, more women were terminated pregnancy before 
term because of deterioration of cardiac function, leading to a higher rate of preterm $\operatorname{birth}(57.1 \%$ versus $\left.27.5 \%, \mathrm{P}_{j} 0.001\right)$ and a higher rate of infants with birthweight $¡ 2500$ grams $\left(56.0 \%\right.$ versus $\left.19.5 \%, \mathrm{P}_{i} 0.001\right)$. It seemed that higher PASP was associated with worse maternal and fetal outcomes.

Besides, we compared maternal and fetal outcomes between women with CHD who had received cardiac surgery and those without Esienmengers' syndrome and prior cardiac surgery (Figure 6 ). There was no significant difference in the rate of maternal death $(1.40 \%$ versus $0.50 \%, \mathrm{P}=0.568)$ and cardiac events $(2.1 \%$ versus $2.40 \%, \mathrm{P}=1.000)$. The infants in the two groups shared similar rate of preterm birth $(23.2 \%$ versus $24.8 \%, \mathrm{P}=0.743)$. However, fewer women were admitted to ICU in those received cardiac surgeries $(22.5 \%$ versus $32.9 \%, \mathrm{P}=0.036)$.

\section{Discussion}

In this retrospective study, we described maternal and fetal outcomes in 603 women with $\mathrm{PH}$ who were admitted to an expert hospital from 1993 to 2019. The outcomes differ in different PH groups and these women are advised to avoid pregnancy in many guidelines ${ }^{[4][5]}$. The overall mortality in the whole study group was $3.0 \%$, which was lower than reported previously ${ }^{[6][7][8]}$. The congenital heart disease is reported to be a leading part of our population, which is more prone to pulmonary hypertension during pregnancy. The mortality differs in different groups, which in Eisenmenger's syndrome is highest (15.2\%), followed by connective tissue disease $(10 \%)$ and idiopathic pulmonary hypertension $(10 \%)$, which may be due to the higher pressure in these groups. Meanwhile, our study also showed that patients with PASP [?]80 mm Hg had a higher mortality than those with PASP ; $80 \mathrm{~mm} \mathrm{Hg}$, which indicates higher PASP causes more deaths.

Maternal blood volume starts to increase during the first trimester, and by the third trimester, it could increase by 40 to 45 percent, which would return to systemic circulation soon after delivery. The rapid hemodynamic changes would result in decompensation in women with heart diseases, and $23^{\sim} 30$ weeks of pregnancy and 1 week especially 24 hours after delivery are the most risk period. Except for 2 women died during pregnancy, $50 \%$ of the deaths occurred within 1 week after delivery. Pulmonary hypertension crisis, pulmonary thrombosis, and right heart failure are common causes of death ${ }^{[9]}$. In our center, the main causes of death are heart failure and pulmonary hypertension crisis. The incidence of heart failure in the study population was $8.5 \%$, which in CHD groups was lower than other groups. In the CHD group, heart failure in the Eisenmenger syndrome group was more prevalent than the other two groups, which also led to a higher rate of admission to ICU. Furthermore, compared with those with PASP $<80 \mathrm{~mm} \mathrm{Hg}$, patients with PASP[?]80 mm Hg had a higher incidence of heart failure.

$\mathrm{PH}$ women were reported to have a higher incidence of obstetric complications than normal population ${ }^{[10]}$. In our study, the incidence of fetal intrauterine growth restriction was 3.5\%, preeclampsia was about $7.2 \%$, which was comparable to international reports $(8.9 \%)^{[6][11]}$. However, it is higher in the PH group caused by connective tissue diseases and idiopathic $\mathrm{PH}$, which to some extent makes it more difficult to treat these patients, and thereby increases the mortality rate.

8.3\% women had abortions and $32.0 \%$ had preterm births. $27.8 \%$ of live-born infants had a birthweight less than 2500 grams. We explored the neonatal outcomes of different etiological groups. Among CNT-PH group, the abortion rate was the highest and the newborn birth weight was the lowest; while in the CHD group, the Eisenmenger syndrome had the highest abortion rate, the highest preterm birth rate and the lowest birth weight. In the PASP [?] $80 \mathrm{~mm} \mathrm{Hg}$, the premature birth rate and the incidence of low birth weight were also much higher than those in the PASP $<80 \mathrm{~mm} \mathrm{Hg}$ group, which again suggesting that the etiology of PH and the severity of PASP are related to the prognosis of the newborn.

Although our center has accepted an increasing number of patients from surrounding area since 1993 and $41.6 \%$ of them were admitted to ICU during the pregnant and postpartum period, mortality had been decreasing from $7.69 \%$ to $2.30 \%$. The use of advanced medication is supposed to the success. Sildenafil (phosphodiesterase inhibitor type 5, PDE5I) and Treprostinil/Remodulin (prostaglandin I2 analogue) are common pulmonary vascular targeted drugs, which could expand blood vessels as endothelin receptor antagonists do, thereby increasing the tolerance of pulmonary arteries. We started to use them in 2005, and 
since then the mortality has decreased. In addition, it is reported that the incidence of venous thromboembolism during pregnancy and puerperium is about $0.05^{\sim} 0.03 \%$, and thrombosis is one of the common causes of death in pregnant women with pulmonary hypertension. According to the ESC guidelines, the risk of venous thromboembolism should be assessed for every pregnant woman ${ }^{[4]}$. For those who need to prevent thrombosis, after eliminating contraindications, low molecular heparin should be used. An overall of $16.9 \%$ women have used Anticoagulant drugs in our center, which has risen from $7.7 \%$ in the first 10 years to $21.4 \%$ in the latest 10 years. There were no reports of thrombosis during pregnancy in our study.

The increasing rate of rescue efficiency was not only associated with advanced medications, but with effective management network for critically ill pregnant women, which has been put into use since 2007, and through which women with severe diseases in local hospital could be transferred. Our hospital is one of the assigned expert centers for pregnancy with cardiac diseases. In our center, over $80 \%$ of pregnant women had regular check-ups during pregnancy, while about one-fifth of women (18.7\%) didn't have regular follow-ups. Women in our center receive electrocardiography and echocardiogram routinely no matter they had complains. As almost half $(41.6 \%)$ of pulmonary hypertension was diagnosed during the pregnant period, we recommend that women should receive echocardiogram after getting pregnant if permitting.

There is no common statement about when and how to terminate the pregnancy. ESC guidelines recommend the optimal mode of delivery in women with PH should be decided depending on the condition of patients by the pregnancy heart team. Although vaginal delivery is considered to have lower risk of hemorrhage, infection and venous thromboembolism compared with delivery by cesarean ${ }^{[12][13]}$, it could also cause pain and increase intrathoracic pressures which may help to decrease venous return. After discussion with the multidisciplinary team including senior obstetrician, anesthetist and expert cardiologist, vaginal delivery was used in patients with aborted fetus and several cases with mild PH. Most of patients (551, 91.4\%) in our study received cesarean section, 21 of which were performed before 28 weeks, especially in those with severe pulmonary hypertension and NYHA heart function of grade IV. The 2018 ESC guidelines also recommend that if there are no contraindications, intraspinal anesthesia should be used. Therefore, our center uses epidural/spine anesthesia in most cases $(473 / 551,85.8 \%)$. In the past, it was believed that local anesthetics would produce volume vasodilatation and decrease the peripheral vascular resistance, leading to a sudden drop in blood pressure. Therefore, in patients who need to maintain systemic circulation and peripheral blood pressure and those who need emergency cesarean section, we use general anesthesia (78/551, 14.2\%), which were used more in Eisenmenger syndrome, connective tissue diseases and idiopathic PH. However, studies have shown that the risk of death in $\mathrm{PH}$ patients receiving general anesthesia is four times that of $\mathrm{PH}$ patients receiving intraspinal anesthesia ${ }^{[14]}$, so the safety of general anesthesia remains to be explored.

Besides, because CHD was reported as the leading cause of maternal death in our study, we explored the maternal and fetal outcomes in different groups of women with CHD. As Eisenmenger's syndrome is contradicted for pregnancy due to its poor outcomes, our study showed that Eisenmenger's syndrome was associated with highest incidence of preterm birth and lowest birthweight, and was responsible for most maternal death in the population of CHD. Ruling out Eisenmenger's syndrome, the admission rate to ICU was lower in pregnant women in the CHD group that has undergone surgery is higher than that in the CHD group that has not undergone surgery. Therefore, CHD patients should try their best to undergo heart surgery before considering pregnancy. However, there was no significant difference in maternal and infant outcomes between the two groups. This may be quite related to the PASP values of the two groups.

In conclusion, due to the low incidence of $\mathrm{PH}$ in the overall population and specific concern in the pregnant women, there was few prospective trials of risk factors in pregnant women with PH. Our study retrospectively analyzed the possible risk factors for maternal mortality. We found that the maternal and infant prognosis in patients with idiopathic PAH and PAH caused by connective tissue diseases was worse than that of the other two groups. In the $\mathrm{PH}$ caused by $\mathrm{CHD}$, Eisenmenger syndrome resulted in the worst prognosis. including the delayed diagnose time, the etiology of disease and severity of PASP. We believe that the cause of PAH and the severity of PASP are related to the maternal and infant outcome. It is of chief importance to manage the patients and improve their life. We hope that these successful management could provide experience for 
hospitals in the rural areas.

\section{Conclusion}

This retrospective study analyzed all PH pregnant women in a pregnancy complicated heart disease center since its establishment in China. The mortality rate was relatively lower than previously reported. Nevertheless, in Eisenmenger syndrome, $\mathrm{PH}$ secondary to connective tissue disease and idiopathic PH, the maternal mortality rate is still very high. In addition to the use of PAH-targeted drugs, we believe that standardized maternal management strategies can also help reduce mortality, including screening for heart disease and effective transport of critically ill patients. The maternal and infant outcome is related to the cause of the disease and the severity of PASP.

\section{Disclosure of interests}

All authors declare no conflict of interest.

\section{Contribution to authorship}

All authors contributed to the design. Chuan Wang collected data and guarantees data integrity. Huixian Miao and Taotao Huang performed statistical analyses. Jianhua Lin and Yunyan Chen reviewed the analysis. Huixian Miao wrote the first draft. All authors contributed to revising and finalisation of the manuscript. Jianhua Lin (corresponding author) guarantees all aspects of the reliability and freedom from bias of the data presented and their discussed interpretation.

\section{Details of ethics approval}

All procedures performed in this study followed the ethical standards set by the Institute Scientific Advisory and Ethical committee (Human Studies), in accordance with the 1964 Declaration of Helsinki and its later amendments. The study was based on the records of the patients identified from the registers, the protocol for the study wsa approved by the Institute Ethics Committee in our hospital (KY2020-057 dated 4 May 2020).

\section{Funding}

This study received no specific grant from any funding agency in the public, commercial or not-for-profit sectors.

\section{Acknowledgements}

None.

\section{Supporting Information}

Additional supporting information may be found online in the Supporting Information section at the end of the article.

\section{References}

[1] Galie, Nazzareno, Humbert M , Vachiery J L , et al. 2015 ESC/ERS Guidelines for the Diagnosis and Treatment of Pulmonary Hypertension[J]. Revista Espaola de Cardiologia (English Edition), 2016, 69(2):177.

[2] Mandalenakis Z, Rosengren A, Skoglund K, Lappas G, Eriksson P, Dellborg M. Survivorship in children and young adults with congenital heart disease in Sweden. JAMA Intern Med 2017;177: 224-230.

[3] Duan R, Xu X, Wang X, Yu H, You Y, Liu X, Xing A, Zhou R, Xi M. Pregnancy outcome in women with Eisenmenger's syndrome: A case series from west china. BMC Pregnancy Childbirth 2016; 16:356.

[4] Regitz-Zagrosek V , Lundqvist C B , Borghi C, et al. 2018 ESC Guidelines for the management of cardiovascular diseases during pregnancy[J]. European Heart Journal, 2018, 39(24):p3147-3197. 
[5] ACOG Practice Bulletin No. 212: Pregnancy and Heart Disease. Obstet Gynecol. 2019 May;133(5):e320e356.

[6] Anish, Keepanasseril, Ajith, et al. Outcome of pregnancies in women with Pulmonary Hypertension: A Single Centre Experience from South India.[J]. Bjog An International Journal of Obstetrics \& Gynaecology, 2019.

[7] Thomas E, Yang J , Xu J , et al. Pulmonary Hypertension and Pregnancy Outcomes: Insights From the National Inpatient Sample[J]. Journal of the American Heart Association, 2017, 6(10):e006144.

[8] Xuefeng, Sun, Jun. Pregnancy and pulmonary hypertension: An exploratory analysis of risk factors and outcomes.[J]. Medicine, 2018.

[9] Bedard E, Dimopoulos K, Gatzoulis MA. Has there been any progress made on pregnancy outcomes among women with pulmonary arterial hypertension? European Heart Journal 2009;30:256-265.

[10] Jafri S, Ormiston ML. Immune regulation of systemic hypertension, pulmonary arterial hypertension, and preeclampsia: shared disease mechanisms and translational opportunities. Am J Physiol Regul Integr Comp Physiol. 2017 Dec 1;313(6): R693-R705. doi: 10.1152/ajpregu.00259.2017. Epub 2017 Oct 4. PMID: 28978513.

[11] Scherrer U, Allemann Y, Rexhaj E, Rimoldi SF, Sartori C. Mechanisms and drug therapy of pulmonary hypertension at high altitude. High Alt Med Biol. 2013 Jun;14(2):126-33. doi: 10.1089/ham.2013.1006. PMID: 23795732.

[12] Hemnes AR, Kiely DG, Cockrill BA, Safdar Z, Wilson VJ, Al Hazmi M, Preston IR, MacLean MR, Lahm T. Statement on pregnancy in pulmonary hypertension from the pulmonary vascular research institute. Pulm Circ 2015;5:435-465.

[13] Martin SR, Edwards A. Pulmonary Hypertension and Pregnancy. Obstet Gynecol. 2019 Nov;134(5):974987. doi: 10.1097/AOG.0000000000003549. Erratum in: Obstet Gynecol. 2020 Apr;135(4):978. PMID: 31599832 .

[14] Rex S, Devroe S. Anesthesia for pregnant women with pulmonary hypertension. Curr Opin Anaesthesiol. 2016 Jun;29(3):273-81. doi: 10.1097/ACO.0000000000000310. PMID: 26978591.

Table

Table 1 Baseline characteristics of 603 women with PH

\begin{tabular}{|c|c|c|c|c|c|}
\hline Variable & Total $\mathrm{n}=603$ & CHD PH n=398 & LHD PH $n=175$ & CNT PH $n=10$ & $\mathrm{I}-\mathrm{PH} \mathrm{n}=20$ \\
\hline Age, years & $28.49 \pm 4.89$ & $27.59 \pm 4.41^{*}$ & $30.23 \pm 5.36^{*}$ & $29.70 \pm 5.60$ & $30.65 \pm 4.78$ \\
\hline Nulliparous, \% & $449(74.5)$ & $312(78.4)^{*}$ & $119(68)^{*}$ & $7(70)$ & $11(55)$ \\
\hline $\begin{array}{l}\text { Timing of } \\
\text { diagnosis, } \%\end{array}$ & & & & & \\
\hline $\begin{array}{l}\text { before } \\
\text { pregnancy, \% }\end{array}$ & $352(58.4)$ & $252(63.8)$ & $96(54.9)$ & $1(10)$ & $3(15)$ \\
\hline $\begin{array}{l}\text { during } \\
\text { pregnancy, \% }\end{array}$ & $251(41.6)$ & $146(36.7)$ & $79(45.1)$ & $9(10)$ & $17(85)$ \\
\hline $\begin{array}{l}\text { Receive } \\
\text { surgery before } \\
\text { pregnancy, } \%\end{array}$ & $192(31.8)$ & $140(35.2)$ & $52(29.7)$ & $0(0)$ & $0(0)$ \\
\hline PASP, $\mathrm{mmHg}$ & $54.39 \pm 24.24$ & $53.10 \pm 24.92^{* *}$ & $51.55 \pm 19.88^{* *}$ & $75.45 \pm 15.48^{* *}$ & $67.15 \pm 37.69$ \\
\hline $\begin{array}{l}\text { PASP[?]49 } \\
\mathrm{mmHg}, \%\end{array}$ & $357(59.2)$ & $245(61.5)$ & $101(57.7)$ & $0(0)$ & $11(55)$ \\
\hline $\begin{array}{l}\text { 50[?]PASP[?]79 } \\
\mathrm{mmHg}, \%\end{array}$ & $155(25.7)$ & $94(23.6)$ & $54(30.9)$ & $5(50)$ & $2(10)$ \\
\hline
\end{tabular}




\begin{tabular}{|c|c|c|c|c|c|}
\hline Variable & Total $\mathrm{n}=603$ & CHD PH n=398 & LHD PH $n=175$ & CNT PH $n=10$ & $\mathrm{I}-\mathrm{PH} \mathrm{n}=20$ \\
\hline $\begin{array}{l}\text { PASP [?]80 } \\
\mathrm{mmHg}, \%\end{array}$ & $91(15.1)$ & $59(14.8)$ & $20(11.4)$ & $5(50)$ & $7(35)$ \\
\hline $\begin{array}{l}\text { NYHA class } \\
\text { III/IV before } \\
\text { pregnancy, \% }\end{array}$ & $17(2.8)$ & $6(1.5)^{* *}$ & $10(5.7)^{* *}$ & $1(10)$ & $0(0)$ \\
\hline $\begin{array}{l}\text { NYHA class } \\
\text { III/IV during } \\
\text { pregnancy, \% }\end{array}$ & $103(17.1)$ & $38(9.5)^{* *}$ & $54(30.9)^{* *}$ & $3(30)$ & $8(40)^{* *}$ \\
\hline $\begin{array}{l}\text { Regular } \\
\text { follow-up } \\
\text { during } \\
\text { pregnancy, \% } \\
\text { Medications }\end{array}$ & $490(81.3)$ & $332(83.4)$ & $138(78.9)$ & $5(50)$ & $15(75)$ \\
\hline Diuretics $^{* *}, \%$ & $196(32.5)$ & $108(27.1)$ & $71(40.6)$ & $7(70)$ & $10(50)$ \\
\hline $\operatorname{Digoxin}^{* *}, \%$ & $69(11.4)$ & $33(8.3)$ & $32(18.3)$ & $0(0)$ & $4(20)$ \\
\hline 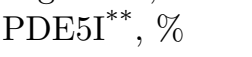 & $43(7.1)$ & $32(8.0)$ & $2(1.1)$ & $2(20)$ & $7(35)$ \\
\hline $\begin{array}{l}\text { Antithrombotic } \\
\text { agents }^{* *}, \%\end{array}$ & $102(16.9)$ & $55(13.8)$ & $39(22.3)$ & $2(20)$ & $6(30)$ \\
\hline
\end{tabular}

*: Was found to be significantly different from other two groups on post hoc analysis $\left(\mathrm{P}_{¡} 0.001\right.$.

**: Was found to be significantly different from other two groups on post hoc analysis $(\mathrm{P} ¡ 0.05$.

Table 2 Baseline characteristics of 398 women with PAH resulting from CHD

\begin{tabular}{|c|c|c|c|c|c|}
\hline Variable & Total $n=398$ & E-CHD n $=46$ & $\mathrm{~A}-\mathrm{CHD} \mathrm{n}=142$ & $\mathrm{O}-\mathrm{CHD} n=210$ & $\mathrm{P}$ \\
\hline Age, years & $27.59 \pm 4.41$ & $25.85 \pm 3.79$ & $27.92 \pm 4.07$ & $27.74 \pm 4.69$ & ¡0.001 \\
\hline nulliparous, \% & $312(78.4)$ & $39(84.8)$ & $119(83.8)$ & $154(73.3)$ & 0.034 \\
\hline $\mathrm{PASP}^{*}, \mathrm{mmHg}$ & $53.10 \pm 24.92$ & $89.32 \pm 25.45$ & $48.47 \pm 21.49$ & $48.64 \pm 20.46$ & ¡0.001 \\
\hline $\begin{array}{l}\text { PASP[?]44 } \\
\mathrm{mmHg}, \%\end{array}$ & $245(61.5)$ & $1(2.2)$ & $99(69.7)$ & $145(69)$ & - \\
\hline $\begin{array}{l}\text { 50[?]PASP[?]79 } \\
\mathrm{mmHg}, \%\end{array}$ & $94(23.6)$ & $13(28.3)$ & $32(22.5)$ & $49(23.3)$ & - \\
\hline $\begin{array}{l}\text { PASP [?] } 80 \\
\mathrm{mmHg}, \%\end{array}$ & $59(14.8)$ & $32(69.6)$ & $11(7.7)$ & $16(7.6)$ & - \\
\hline $\begin{array}{l}\text { NYHA class } \\
\text { III/IV before } \\
\text { pregnancy, } \%\end{array}$ & $6(1.5)$ & $2(4.3)$ & $1(0.7)$ & $3(1.4)$ & 0.204 \\
\hline $\begin{array}{l}\text { NYHA class } \\
\text { III/IV at } \\
\text { pregnancy, \% }\end{array}$ & $38(9.5)$ & $16(34.8)$ & $7(4.9)$ & $15(7.1)$ & ¡0.001 \\
\hline $\begin{array}{l}\text { Regular } \\
\text { follow-up } \\
\text { during } \\
\text { pregnancy, \% } \\
\text { Medications }\end{array}$ & $332(83.4)$ & $25(54.3)$ & $140(91.5)$ & $177(84.3)$ & ¡0.001 \\
\hline Diuretics, $\%$ & $108(27.1)$ & $28(60.9)$ & $26(18.3)$ & $54(25.7)$ & ¡0.001 \\
\hline Digoxin, \% & $33(8.3)$ & $9(19.6)$ & $10(7.0)$ & $14(6.7)$ & 0.025 \\
\hline PDE5I, \% & $32(8.0)$ & $10(21.7)$ & $13(9.2)$ & $9(4.3)$ & 0.001 \\
\hline
\end{tabular}




\begin{tabular}{llllll}
\hline Variable & Total $\mathrm{n}=398$ & E-CHD $\mathrm{n}=46$ & A-CHD $\mathrm{n}=142$ & O-CHD $\mathrm{n}=210$ & $\mathrm{P}$ \\
\hline $\begin{array}{l}\text { Antithrombotic } \\
\text { agents, \% }\end{array}$ & $55(13.8)$ & $10(21.7)$ & $26(18.3)$ & $19(9.0)$ & 0.012 \\
\hline
\end{tabular}

*: Was found to be significantly different from other two groups on post hoc analysis $\left(\mathrm{P}_{¡} 0.001\right.$.

Table 3 Maternal and fetal outcomes in 603 women with PH

\begin{tabular}{|c|c|c|c|c|c|c|}
\hline Variable & Total $n=603$ & $\begin{array}{l}\text { CHD PH } \\
\mathrm{n}=398\end{array}$ & $\begin{array}{l}\text { LHD PH } \\
\mathrm{n}=175\end{array}$ & CNT PH n=10 & $\mathrm{I}-\mathrm{PH} \mathrm{n}=20$ & $\mathrm{P}$-value \\
\hline Abortion, \% & $50(8.3)$ & $26(6.5)$ & $15(14.5)$ & $7(70)$ & $2(10)$ & ¡0.001 \\
\hline $\begin{array}{l}\text { Gestational } \\
\text { age at } \\
\text { delivery, } \\
\text { weeks }\end{array}$ & $36.87 \pm 2.71$ & $37.12 \pm 2.49$ & $36.68 \pm 2.83$ & $32.91 \pm 2.36$ & $33.92 \pm 3.70$ & ¡0.001 \\
\hline $\begin{array}{l}\text { Cesarean } \\
\text { rate, } \%\end{array}$ & $551(91.4)$ & $371(93.2)$ & $158(90.3)$ & $7(70)$ & $15(75)$ & 0.004 \\
\hline $\begin{array}{l}\text { GA during } \\
\text { cesarean, \% } \\
\text { Maternal } \\
\text { outcomes }\end{array}$ & $78(14.2)$ & $42(11.3)$ & $26(16.5)$ & $4(57.1)$ & $6(40)$ & ¡0.001 \\
\hline $\begin{array}{l}\text { Maternal } \\
\text { death, \% }\end{array}$ & $18(3.0)$ & $10(2.5)$ & $5(2.9)$ & $1(10)$ & $2(10)$ & 0.105 \\
\hline $\begin{array}{l}\text { Heart } \\
\text { failure, \% }\end{array}$ & $51(8.5)$ & $15(3.8)$ & $30(17.1)$ & $2(20)$ & $4(20)$ & ¡0.001 \\
\hline $\mathrm{PE}, \%$ & $43(7.2)$ & $24(6.0)$ & $10(5.7)$ & $3(30)$ & $6(30)$ & ¡0.001 \\
\hline FGR & $21(3.5)$ & $19(4.8)$ & $0(0)$ & $0(0)$ & $2(10)$ & ¡0.001 \\
\hline $\begin{array}{l}\text { Admission } \\
\text { to ICU, \% } \\
\text { Fetal } \\
\text { outcomes }\end{array}$ & $251(41.6)$ & $143(35.9)$ & $83(47.4)$ & 10(100) & $15(75)$ & ¡0.001 \\
\hline $\begin{array}{l}\text { Birthweight, } \\
\text { g }\end{array}$ & $2715 \pm 675.00$ & $2760 \pm 653.89$ & $2686.80 \pm 681.44$ & $1861.67 \pm 254.18$ & $2169.17 \pm 787.35$ & 0.001 \\
\hline $\begin{array}{l}\text { Birthweight } \\
\text { ¡2500g, \% }\end{array}$ & $156(27.8)$ & $92(24.5)$ & $54(32.9)$ & $3(100)$ & $7(38.9)$ & 0.005 \\
\hline $\begin{array}{l}\text { Preterm } \\
\text { delivery, \% }\end{array}$ & $193(32.0)$ & $111(27.9)$ & $66(37.7)$ & $3(30)$ & $13(65)$ & 0.001 \\
\hline
\end{tabular}

Table 4 Maternal and fetal outcomes in 398 women with PAH resulting from CHD

\begin{tabular}{llllll}
\hline Variable & Total $\mathrm{n}=398$ & $\mathrm{E}-\mathrm{CHD} \mathrm{n}=46$ & $\mathrm{~A}-\mathrm{CHD} \mathrm{n}=142$ & $\mathrm{O}-\mathrm{CHD} \mathrm{n}=210$ & $\mathrm{P}$ \\
\hline $\begin{array}{l}\text { Gestational } \\
\begin{array}{l}\text { age at delivery } \\
\text { Cesarean rate }\end{array}\end{array}$ & $36.08 \pm 4.74$ & $30.54 \pm 7.01$ & $36.63 \pm 3.97$ & $36.92 \pm 3.71$ & $\mathrm{i} 0.001$ \\
$\begin{array}{l}\text { GA during } \\
\text { cesarean, } \%\end{array}$ & $42(11.3)$ & $39(84.8)$ & $133(93.7)$ & $199(94.8)$ & 0.06 \\
$\begin{array}{l}\text { Maternal } \\
\text { outcomes }\end{array}$ & & $18(45.0)$ & $8(6.0)$ & $17(8.5)$ & $i 0.001$ \\
\end{tabular}




\begin{tabular}{|c|c|c|c|c|c|}
\hline Variable & Total $\mathrm{n}=398$ & E-CHD n=46 & $\mathrm{A}-\mathrm{CHD} \mathrm{n}=142$ & $\mathrm{O}-\mathrm{CHD} \mathrm{n}=210$ & $\mathrm{P}$ \\
\hline $\begin{array}{l}\text { Maternal } \\
\text { death, } \%\end{array}$ & $10(2.5)$ & $7(15.2)$ & $2(1.4)$ & $1(0.5)$ & ¡0.001 \\
\hline $\begin{array}{l}\text { Heart failure, } \\
\%\end{array}$ & $15(3.8)$ & $7(15.2)$ & $2(2.1)$ & $5(2.4)$ & 0.001 \\
\hline $\mathrm{PE}, \%$ & $24(6.0)$ & $3(6.7)$ & $9(6.3)$ & $12(5.7)$ & 0.869 \\
\hline FGR, \% & $19(4.8)$ & $5(11.1)$ & $4(2.8)$ & $10(4.8)$ & 0.074 \\
\hline $\begin{array}{l}\text { Admission to } \\
\text { ICU, } \%\end{array}$ & $143(35.9)$ & $42(91.3)$ & $32(22.5)$ & $69(32.9)$ & ¡0.001 \\
\hline \multicolumn{6}{|l|}{ Fetal outcomes } \\
\hline Abortion, \% & $26(6.5)$ & $13(28.3)$ & $6(4.2)$ & $7(3.3)$ & ¡0.001 \\
\hline Birthweight, g & $2760 \pm 653.89$ & $1670 \pm 858.28$ & $2773.37 \pm 755.10$ & $2779.16 \pm 685.53$ & ¡0.001 \\
\hline $\begin{array}{l}\text { Birthweight } \\
\text { ¡2500g, \% }\end{array}$ & $92(24.5)$ & $25(75.8)$ & $26(19.1)$ & $38(18.7)$ & ¡0.001 \\
\hline $\begin{array}{l}\text { Preterm } \\
\text { delivery, \% }\end{array}$ & $111(27.9)$ & $26(56.5)$ & $33(23.2)$ & $52(24.8)$ & ¡0.001 \\
\hline
\end{tabular}

Figure

\section{Hosted file}

image1.emf available at https://authorea.com/users/373154/articles/490923-outcome-ofpregnancies-in-pregnant-women-with-pulmonary-hypertension-a-single-center-experiencefrom-east-china

Figure1 the distribution of use of medications based on years

\section{Hosted file}

image2.emf available at https://authorea.com/users/373154/articles/490923-outcome-ofpregnancies-in-pregnant-women-with-pulmonary-hypertension-a-single-center-experiencefrom-east-china

Figure 2 Indications of cesarean in 551 women with PH

\section{Hosted file}

image3.emf available at https://authorea.com/users/373154/articles/490923-outcome-ofpregnancies-in-pregnant-women-with-pulmonary-hypertension-a-single-center-experiencefrom-east-china

Figure 3 The etiology of 18 deaths

\section{Hosted file}

image4.emf available at https://authorea.com/users/373154/articles/490923-outcome-ofpregnancies-in-pregnant-women-with-pulmonary-hypertension-a-single-center-experiencefrom-east-china

Figure 4 The distribution of number of deaths and mortality

\section{Hosted file}

image5.emf available at https://authorea.com/users/373154/articles/490923-outcome-ofpregnancies-in-pregnant-women-with-pulmonary-hypertension-a-single-center-experiencefrom-east-china 
Figure 5 Comparison of maternal and fetal outcome in the study population based on the PASP.

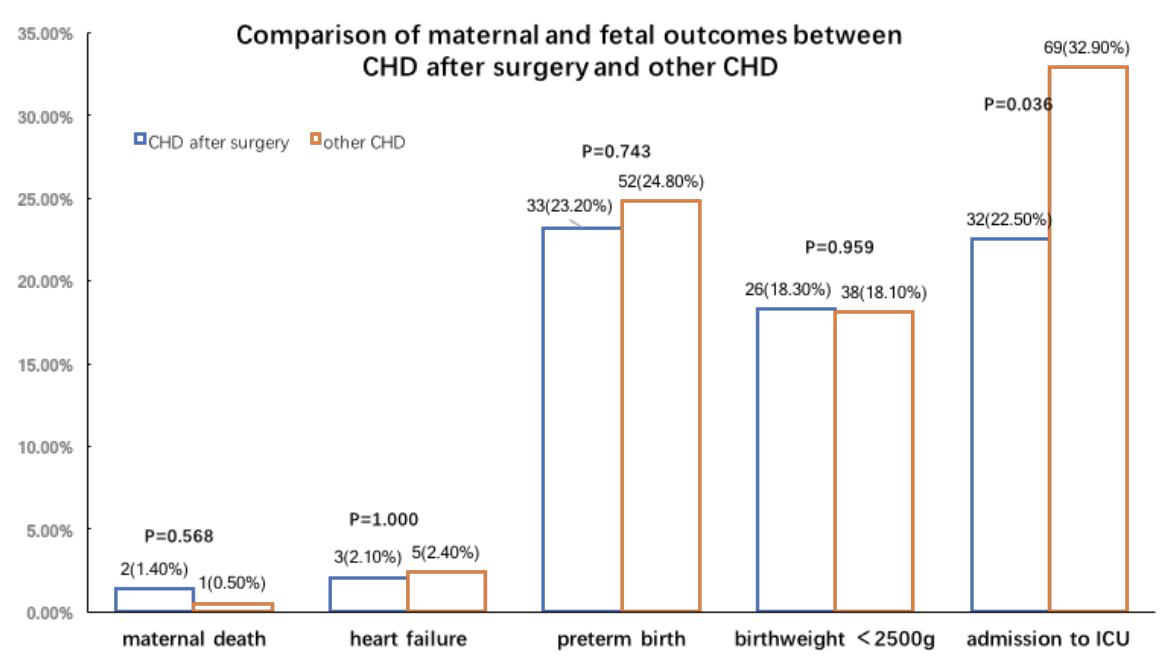

Figure 6 Comparison of maternal and fetal outcomes between CHD after surgery and other CHD 